Int. J. Dev. Biol. 57: 651-657 (2013)

doi: 10.1387/ijdb.130144ah

\title{
Engineered plant minichromosomes
}

\author{
ANDREAS HOUBEN*, MICHAEL F. METTE, CHEE H. TEO\#, \\ INNA LERMONTOVA and INGO SCHUBERT
}

Leibniz Institute of Plant Genetics and Crop Plant Research (IPK), 06466 Stadt Seeland OT Gatersleben, Germany

\begin{abstract}
Minichromosomes offer an enormous potential for plant breeding and biotechnology, because they may simultaneously transfer and stably express multiple genes. Segregating independently of their host chromosomes, they provide a platform for accelerating plant breeding. Minichromosomes can be established from cloned components in vivo (bottom up) or via engineering of natural chromosomes (top down). When they possess functional centromeres and telomeres, they should be stably inherited, but their meiotic transmission rate is below that of endogenous chromosomes. To achieve the customized generation and control the regular transmission of minichromosomes are important challenges for applied research in chromosome biology. Here, construction and biology of plant minichromosomes are compared with data available for yeast and animal systems.
\end{abstract}

KEY WORDS: minichromosome, engineered chromosome, telomere seeding, vector, centromere

\section{Introduction}

A number of plant species of commercial interest have been transformed by means of Agrobacterium tumefaciens-mediated, biolistic, or other gene transfers. However, these methods have several limitations. For example, they allow insertion of single or a few genes mostly at random chromosomal positions. Complex traits cannot be transferred in a coordinated manner. Furthermore, the integrity of the host genome can be disturbed by transgene insertion. These drawbacks stimulated the development of gene targeting to predetermined chromosome positions on the one hand and of chromosome-based vector systems on the other hand. Whereas the former approach still restricts the size of the transferred genes, the latter is suitable for transfer of large genes, gene complexes, and/or multiple genes together with regulatory elements for safe, controlled, and persistent expression. Furthermore, minichromosome vectors avoid rearrangements that are often linked with transgene insertion into native chromosomes (Aufsatz et al., 2002; Pecinka et al., 2005; Kinoshita et al., 2010). Additionally, engineered chromosomes could be used to address basic questions concerning the function of specific chromosomal domains, such as centromeres (Nakano et al., 2008). The centromere is the spindle attachment point in cell division and is essential for faithful chromosome segregation. Chromosome engineering has been applied successfully in yeasts and mammals, but has lagged behind in plants.

Considerable progress has been made in developing chromosome-based vector systems either by artificial composition of cloned chromosomal constituents into functional chromosomes ("bottom-up" approach) or by engineering endogenous chromosomes ("top-down" approach). Such engineered minichromosomes have been used for the development of chromosome-based vector systems (Grimes and Monaco, 2005).

\section{"Bottom-up" approaches for the generation of artificial chromosomes}

The "bottom-up" strategy relies on cell-mediated chromosome assembly after transfection of a cell line with recombinant constructs comprising cloned centromeric sequences and a selectable marker gene, with or without telomeric repeats. This method is well established in yeast (Murray and Szostak, 1983; Clarke and Carbon, 1985) and mammalian cells (Harrington et al., 1997; Ikeno et al., 1998; Fig. 1A). However, the process of de novo chromosome assembly within cells is hard to control and has been achieved only in a limited number of mammalian cell lines (Irvine et al., 2005). Application of the "bottom-up" strategy in plants (Carlson et al., 2007; Ananiev et al., 2009) has not yet yielded sufficiently robust

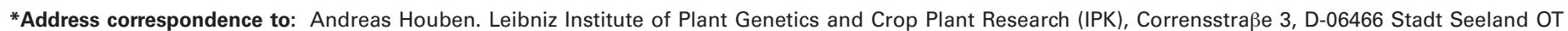
Gatersleben, Germany, Tel. +49-39482-5486. Fax +49-39482-5139. E-mail: houben@ipk-gatersleben.de

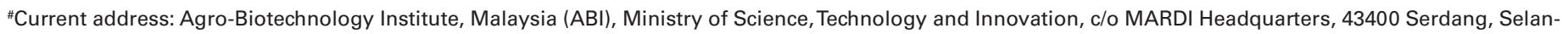
gor, Malaysia.
}

Final, author-corrected PDF published online: 16 October 2013.

ISSN: Online 1696-3547, Print 0214-6282 
solutions. Whether the claimed in vivo assembly of autonomous maize minichromosomes is reliable (Carlson et al., 2007) is still a matter of debate (Houben et al., 2008; Birchler et al., 2010; Gaeta et al., 2012).

Our limited understanding of centromere function and maintenance is one of the obstacles to generate artificial chromosomes. In a study in rice (Oryza sativa), transfer of megabase pair-sized centromeric repeat arrays from either maize (Zea mays) or rice did not result in de novo formation of stable centromeres (Phan et al., 2007). Transgenic plants only exhibited inserted centromeric sequences without evidence of centromeric activity. Also transformation of the yeast Candida albicans with its own centromeric DNA (85 kb) was incapable of recruiting the centromeric histone variant cen $\mathrm{H} 3$ and to form functionally active centromeres at these sequences (Baum et al., 2006). The presence of cenH3 defines the chromosomal site for kinetochore complex assembly at active centromeres. Although plant centromeric sequence arrays are often very long (Jin et al., 2004), a functional centromere might be only a few hundred $\mathrm{kb}$ in size (Nagaki et al., 2004). Moreover, centromeric repeats of barley (Hordeum vulgare) have been shown to be neither necessary nor sufficient to establish a centromere (Nasuda et al., 2005). The idea that the primary DNA sequence alone does not determine the centromere identity (Vig, 1994) is supported by the rapid inactivation of the second centromere of dicentric chromosomes with two sequence-identical centromeres in maize (Han et al., 2006) or with two different ones on interspecific-translocation chromosomes in hybrid progenies of wheat (Triticum aestivum) and barley (Nasuda et al., 2005). Rather, a specific epigenetic mark is seemingly responsible for the centromere specification (Karpen and Allshire, 1997). Although substitution of the histone $\mathrm{H} 3$ by cenH3 in centromeric nucleosomes is crucial for kinetochore formation, we do not know which is the original trigger for this substitution when a new centromere is initiated or why and how cenH3 gets lost when a centromere becomes inactive. In general, the amount of cenH3 present in an individual centromere seems to determine the amount of cenH3 loaded during the next division cycle to the same centromere (Raychaudhuri et al., 2012).

\section{“Top-down” approaches}

\section{Chromosome truncation by telomere seeding}

Modification of existing chromosomes to generate chromosomebased vectors can be achieved by several different routes. As shown first by Farr et al., (1991), introduction of cloned telomeric repeats into cultivated cells may truncate the distal portions of chromosomes by the formation of new telomeres at integration sites. This elegant in vivo approach was an important step toward the construction of a gene delivery system based on engineered human chromosomes (Lim and Farr, 2004). A comparable telomere seeding strategy was used for the generation of truncated chromosomes in the frog Xenopus laevis (Wuebbles and Jones, 2007), the yeast Candida albicans (Kabir and Rustchenko, 2005), and in two species of the protozoon genus Leishmania (Tamar and Papadopoulou, 2001).

For the first time in plants, Yu et al., (2006) and Vega et al., (2008) adapted telomere seeding to form truncated maize chromosomes (reviewed in Birchler etal., 2010; Fig. 1B). T-DNA constructs containing arrays of Arabidopsis thaliana-type telomere repeats (Richards and Ausubel, 1988) were used to transform maize immature embryos to reduce the size of endogenous chromosomes. Subsequently, a reporter gene was transferred from one to another engineered minichromosome via a Cre/Lox-based site-specific recombination system included in the transgenes (Yu et al., 2007). Later, telomere-mediated chromosomal truncation was employed for the generation of minichromosomes in A. thaliana (Nelson et al., 2011; Teo et al., 2011), barley (Kapusi et al., 2011), and rice (Xu et al., 2012). As the telomere repeat sequence is highly conserved among plants, telomere-mediated truncation should be applicable to most plant species.

Minichromosome generation viachromosome truncation by telomere seeding requires at least three components: (i) Arabidopsistype telomere sequences for truncation, (ii) selection markers that allow the identification of transgenic events, and (iii) a site-specific recombination system to mediate future gene transfer into the minichromosome. These elements are usually preassembled in one construct. The three elements could be mixed to cotransform plant
Minichromosome formation via:

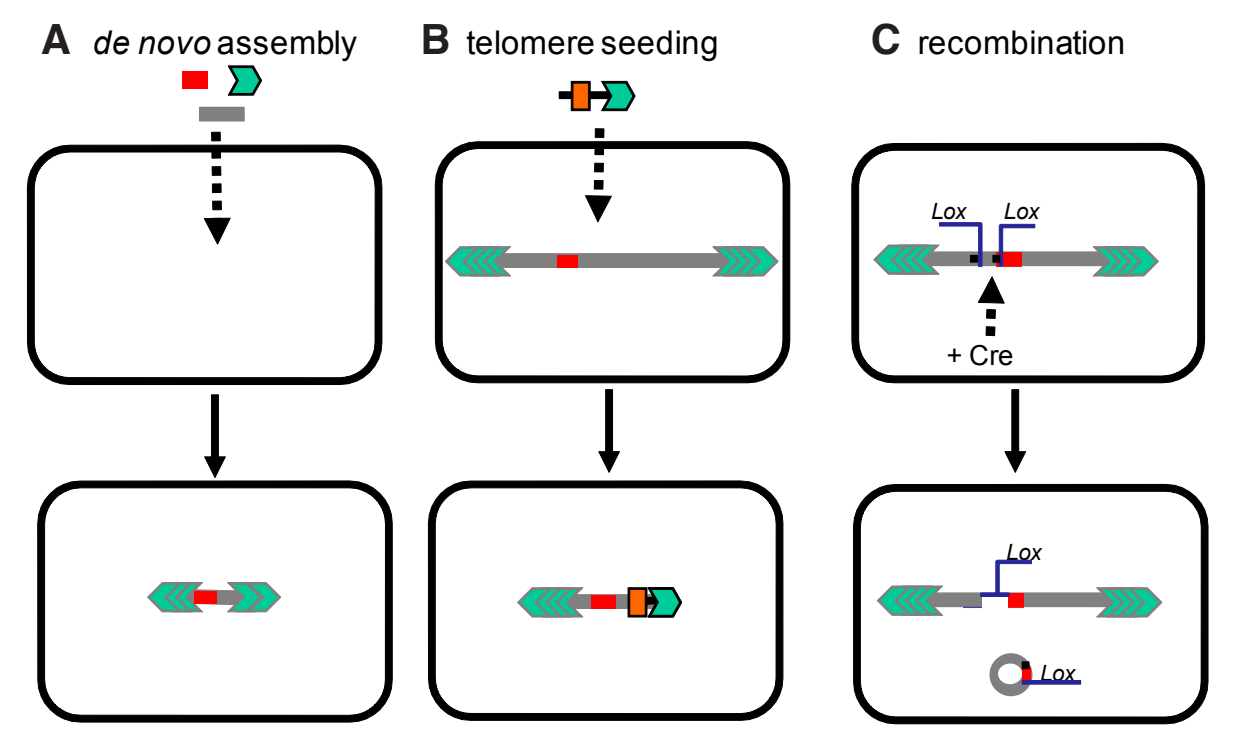

Fig. 1. Strategies for minichromosome generation. (A) Potential de novo assembly of a minichromosome after transformation of cells with centromeric, telomeric, and genomic sequences. This approach has been used for the generation of mammalian and yeast artificial chromosomes. (B) Truncation of a native chromosome by telomere seeding. A vector containing Arabidopsis-type telomere repeats, and a homologous recombination site has been used for fragmentation of recipient chromosomes. (C) Engineering of a mini ring-chromosome by site-specific recombination. Introduction of the Cre recombinase excises the sequence between two transgenic Lox sites. The excised sequence, including part of the centromere, circularizes and forms a ring-minichromosome that is stable without the presence of telomeres. Red box, centromere; green box, telomere; orange box, recombination cassette; greybox, genomic DNA; and black box, T-DNA. 
cells in a biolistic approach, which resulted in efficient chromosomal truncations in rice (Xu et al., 2012). Thanks to the cotransformation, instability problems of constructs harboring long telomere arrays could be overcome and time in vector construction could be saved.

Thus far, targeting of genomic sequences by homologous recombination is inefficient in seed plants (Reiss, 2003), due to the impossibility to target the integration of constructs containing cloned telomere repeats to particular chromosome sites as used in mammalian cells (Lim and Farr, 2004). Therefore, because the chromosomal truncation sites are random, sequencing of T-DNAflanking regions or in situ hybridization with chromosome-specific marker sequences is required to determine which chromosome of a complement has been truncated. In the future, targeting the integration of the T-DNA-containing telomeric repeat array to centromere-near positions by inducing DNA double-strand (ds) breaks (DSBs) in a sequence-specific manner could increase the precision of the chromosome engineering.

Our knowledge on the mechanism of telomere-mediated chromosome truncation in plants is still limited. Nevertheless, nonhomologous end joining between the proximal break end of the chromosome and the transgene border opposite the telomeric sequences seemingly causes the truncation and mediates the formation of a new telomere by extending the transgenic telomere sequences (reviewed in Birchler et al., 2010).

The insertion of Agrobacterium-derived T-DNA into the host plant genome starts with the fusion of single-stranded (ss) T-DNA with chromosomal DNA by the annealing of its left border end to a region with microhomology adjacent to a DSB site (Tinland and Hohn, 1995; Tzfira et al., 2004; Teo et al., 2011; Fig. 2). For the formation of the "conventional" T-DNA integration event, the right border end is then annealed to a second region with microhomology at the opposite side of the DSB to close the break site. In the case of a telomere seeding event, the binding of ss or ds telomerebinding proteins (ss or ds TBPs) to the telomere repeats leads to the transition from DSB repair to telomere healing, eventually forming a functional telomere at the break site (Teo et al., 2011). By exploiting the genetic tractability of $A$. thaliana, Nelson et al., (2011) investigated the role of the nonhomologous end joining machinery in transgene-mediated chromosomal truncation. By means of different available genetic mutants (Attert, Atku70, and Atlig4), the telomerase AtTERT was shown to inhibit telomere seeding, whereas AtKu70 and AtLIG4 played important roles in promoting it. These studies concluded that multiple competing pathways are involved in transgene-mediated chromosomal truncation. Although the frequency of chromosomal truncation is lower in plants than that in mammalian cells, testing different constructs and genetic backgrounds might result in improved truncation efficiency. Because the truncation efficiency of vertebrate chromosomes is the highest in a hyper-recombinogenic chicken (Gallus gallus) cell line (Buerstedde and Takeda, 1991), plant accessions or mutants with a high somatic recombination frequency might be host organisms of choice.

The lack of meiotic pairing of maize minichromosomes produced by telomere seeding with their progenitor chromosome(s) suggests that such small chromosomes have a low chance to recombine with a normal chromosome and, therefore, can be used as starting material to engineer plant chromosomes (Yu et al., 2007). However, the lack of pairing between homologous minichromosomes is apparently a handicap for stable trans-generational inheritance.
Whereas too large chromosomes (with arms longer than half of the average spindle axis length) are often not correctly transmitted through mitotic divisions (Schubert and Oud, 1997), the bottleneck for transmission of too small chromosomes seems to be meiosis. The lowest chromosome size limits for Mendelian transmission rates seem to vary among species, from approximately $50 \mathrm{~kb}$ in yeast to $<5 \%$ of the genome size of field bean (Vicia faba) (Schubert, 2001). Interestingly, birds stably inherit endogenous microchromosomes of approximately $2 \mathrm{Mb}$ (Burt, 2002), but below $550 \mathrm{~kb}$ they get lost frequently already during mitosis in DT40 cells (Spence et al., 2006). At present, we do not know whether the lack of meiotic pairing and/or recombination, the absence of a "lateral support" for centromeres to maintain centromeric cohesion, a combination of these two, or other unrelated reasons are responsible for the impaired meiotic transmission of very small chromosomes.

\section{Generation of satellite-DNA based minichromosomes}

Another approach to engineer endogenous chromosomes in mammalian cells is based on the generation of dicentric chromosomes by in vivo amplification of (peri)centromeric satellite DNA and other host sequences, such as ribosomal DNA, together with transgene sequences after integration of transfected plasmids into the pericentromeric regions of the $7 \mathrm{~S}$ chromosome arm of mouse (Mus musculus) (Keresö et al., 1996). Although a second centromere on a chromosome in transgenic cell lines of the hybrid mouse-Chinese hamster (Cricetulus griseus) could seemingly be generated reproducibly, the underlying mechanism is not well understood. The breakage products of such dicentrics can be stabilized by healing the ends via telomere addition. The resulting engineered chromosomes ("satellite DNA-based artificial chromosomes") are composed mainly of amplified satellite repeats and ribosomal DNA, interspersed with co-amplified transfected foreign DNA (Csonka et al., 2000). Integrated exogenous genetic material was expressed, although the resulting minichromosomes were heterochromatic. Such minichromosomes can be isolated by flow cytometry and then transferred into different cell types (Wilson and Thompson, 2007). "Satellite DNA-based artificial chromosomes" were also introduced into embryos via microinjection to generate transgenic animals that could transmit the artificial chromosome through their germline to the progeny for multiple generations (Aguilera and Gómez-González, 2008). A similar process by structural rearrangements combined with $5 S$ ribosomal DNA amplification has been proposed for the origin of a natural B chromosome in Plantago lagopus (round headed plantain) (Dhar et al., 2002) from a trisomic A chromosome.

\section{De novo generation of centromeres at tandem repeats}

Recently, a novel approach has been described for the engineering of Drosophila melanogaster (fruit fly) chromosomes with the LacO/Lacl system, based on the artificial targeting of the lactose repressor (Lacl)-tagged cenH3 of Drosophila (CID) to transgenic tandem repeat arrays of the lactose operator $(\mathrm{LaCO})$ sequences (Mendiburo et al., 2011). Notably, the tethering of the fusion protein CID-green fluorescent protein (GFP)-Lacl alone is sufficient for the ectopic centromere formation, including the assembly of a functional kinetochore in Drosophila. Moreover, the CID-GFP-Lacl-bound extrachromosomal LacO plasmids were able to assemble kinetochores and to bind microtubules. The assembled "minichromosomes" were mitotically stable for several 
cell generations, even after eliminating CID-GFP-Lacl (Mendiburo et al., 2011). A similar LacO/Lacl system has been applied also to human cells to induce an ectopic kinetochore assembly (Barnhart et al., 2011; Gascoigne et al., 2011). Barnhart et al., (2011) reported that the human cenH3 (CENP-A) chaperone Holliday junction protein (HJURP) is sufficient to form a functional de novo kinetochore in human tumor (HeLa) cells. The Lacl-HJURP fusion protein enabled the direct stable recruitment of CENP-A to a $\mathrm{LacO}$ array at a noncentromeric locus and the formation of a functional ectopic centromere. In another study, replacement by Lacl of the DNA-binding regions of two constitutive kinetochore components, CENP-C and CENP-T, recruited these two components to the ectopic loci, resulting in a CENP-A-independent kinetochore assembly (Gascoigne et al., 2011).

Given the high degree of conservation of kinetochore components across species (Houben and Schubert, 2003), a similar strategy to

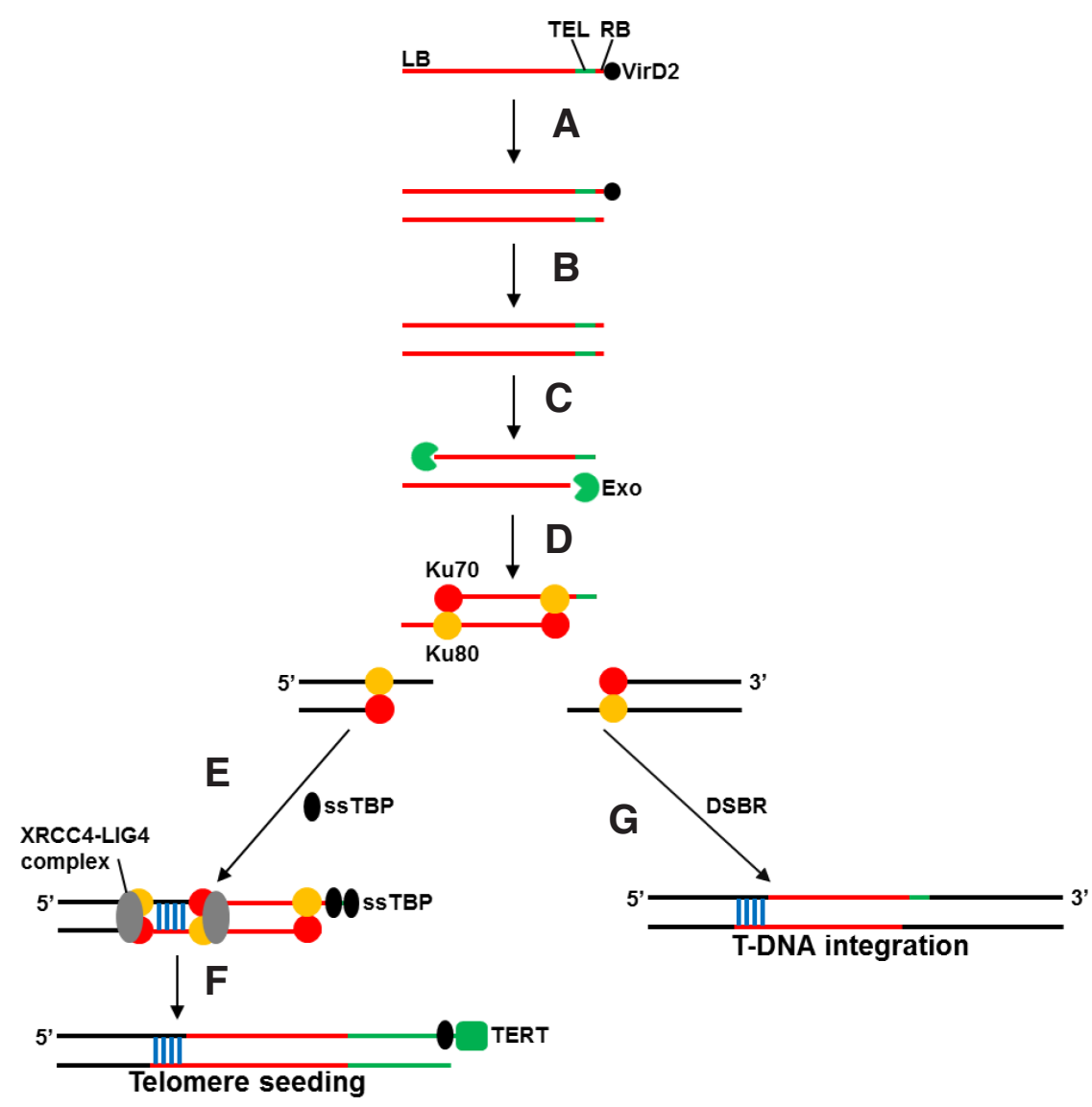

Fig. 2. Model for telomere seeding in plants. (A) A single-stranded (sS) T-DNA transferred by Agrobacterium is converted rapidly to a double-stranded (ds) T-DNA intermediate within the plant cell nucleus. (B) The virulence protein VirD2 is removed from the ds T-DNA intermediate. (C) Processing of unprotected ds ends of the T-DNA intermediate exposes the telomere repeats. (D) Binding of the Ku70/80 heterodimer to both ends of the ds T-DNA intermediate protects the ends from further degradation. (E) Binding of the XRCC4-AtLIG4 complex joints the ds T-DNA intermediate with the host DNA, whereas binding of ss telomere-binding proteins (TBPS) at the ss telomere repeat prevents the activity of DSB repair (DSBR) machinery at the telomeric sequences. (F) The plant telomerase (TERT) adds new telomere repeats to form a functional de novo telomere. (G) DSBR, instead of telomere seeding, results in stable T-DNA integration. The red, black, and green lines represent the T-DNA, the host DNA, and the telomeric repeats (TELs), respectively, near the right border (RB) site of the T-DNA. Areas of microhomology between T-DNA and plant DNA are indicated by vertical blue lines. design engineered plant chromosomes seems promising. Successul application of the LacO/Lacl system for GFP tagging of distinct ( Jovtchev et al., 2008, 2011). Indeed, preliminary data suggest that the $\mathrm{LacO} / \mathrm{Lacl}$ system can be exploited also for ectopic plant kinetochore assembly, providing dicentric chromosomes for subsequent splitting into artificial minichromosomes (Teo et al., 2013).

\section{Engineering of mini ring chromosomes}

Alternative routes to generate artificial minichromosomes have thaliana plant, individuals were found with different chromosome rearrangements, involving the transgene locus. Further rearrangeromosomes eventually gave rise to a dicentric ring-shaped minichromosome of approximately $4 \mathrm{Mb}$ that originated from a half-sized monocentric ring by sister chromatid exchange. The dicentric ring consisted of approximately $570 \mathrm{~kb}$ of centromeric repeats, $270 \mathrm{~kb}$ of mitochondrial DNA, and parts of the short arm of chromosome 2 , all in duplicate. The initial ring chromosome (Murata et al., 2008; Yokota et al., 2010) and its spontaneous derivatives (Yokota et al., 2011) could be meiotically transmitted, albeit at a much lower frequency than wild-type chromosomes.

In follow-up work, the deliberate construction of a monocentric small ring chromosome in $A$. thaliana was attempted. As starting point, a T-DNA was inserted into the centromere of chromosome 2 that contained two Lox recognition sites for Cre-mediated recombination, of which one was flanked by Dissociation (Ds) elements (Fig. 1C). Introgression of a transgene expressing the maize Activator (Ac) transposase induced "in cis transposition" of the latter Loxsite, resulting in the presence of two Lox sites in the same orientation at different positions in the centromeric region of chromosome 2 . In a second step, expression of the Cre recombinase was used to excise the region between these Lox sites to form a ring chromosome of approximately $2.85 \mathrm{Mb}$, including approximately $250 \mathrm{~kb}$ centromeric, $>250 \mathrm{~kb}$ pericentromeric, and other sequences of the short arm of chromosome 2 (Murata et al., 2013).

This mini-ring was found in $>95 \%$ of mitotically dividing cells, remained monocentric (i.e., did not become double-sized and dicentric due to an odd number of sister chromatid exchanges) in $72-85 \%$ of the tested cells and did not pair to chromosome 2 during meiosis. Transmission to the next generation was in the range of $41 \%$ for the progeny obtained by self-pollination, with more efficient transfer via pollen $(86 \%$ and $28 \%$ from plants homozygous for the deleted version of chromosome 2 and for the intact chromosome 2 , respectively) than via the female parent $(15 \%$ and $11 \%$ from the same genotypes as above, 
respectively), when reciprocal crosses with the wild-type were done.

\section{$A$ versus $B$ chromosomes}

$B$ chromosomes might become a major player for the generation of engineered chromosomes because of their unique features. B chromosomes are supernumerary, dispensable chromosomes present in many plant and animal species that, by definition, do not pair with any of the standard A chromosomes at meiosis and have irregular inheritance modes (Jones and Houben, 2003). Regarding the potential use of mini-B chromosomes as vectors, it is important to know that B chromosomes usually have little effect on an individual's phenotype. Only when B chromosomes are numerous, they can reduce vigor (Puertas, 2002). Thus, engineered mini-B chromosomes enable studies on gene dosage effects. After telomere sequence-mediated truncation, the survival rate was enhanced when $B$ rather than $A$ chromosomes of maize were affected (Yu et al., 2007), most likely, because they are genetically inert. Stable transgene expression from $A$ as well as from $B$ chromosome-derived minichromosomes suggested that when it occurs, gene inactivation on $\mathrm{B}$ chromosomes is at least not a rapid process. It would be interesting to compare transgene expression on A and on B chromosome-derived minichromosomes over several generations. However, it needs to be taken into account that the evolutionary history of $\mathrm{B}$ chromosomes depends on the species and that the DNA composition of each supernumerary chromosome is unique. For instance, the B chromosomes of rye (Secale cereale) that contains several thousand genic sequences with similarity to A chromosome-located genes, show a weak transcriptional activity (Carchilan et al., 2009; Martis et al., 2012). Therefore, whether $\mathrm{B}$ chromosomes, in general, are suitable to generate engineered chromosomes for transgene expression remains to be answered.

To ensure the viability of plants with an A chromosome-derived minichromosome, the truncation event should take place in a polyploid background. Alternatively, aneuploids with an increased copy number of the target chromosome can be utilized. Furthermore, a B chromosome-derived vector minichromosome might reveal a potentially higher transmission frequency than that expected according to Mendelian rules. Intact B chromosomes can display an intrinsic postmeiotic drive via nondisjunction at pollen mitosis, leading to a preferential accumulation of $B$ chromosomes in generative nuclei (Carlson, 1978). Truncation of a B chromosome that eliminates nondisjunction confers inheritance characteristics to the resulting mini-B chromosome equal to those of any normal A chromosome. However, nondisjunction of such defective $B$ chromosomes can be restored in trans by the presence of normal B chromosomes that supply factors necessary for nondisjunction encoded on their long arms. Early studies indicated that this non-Mendelian accumulation mechanism of B chromosomes in rye also occurs in wheat (Müntzing, 1970).

\section{Transgeneration stability of minichromosomes}

Since most of the engineered animal chromosomes have been generated and maintained in cell cultures, our knowledge on their meiotic transmissibility is rather scarce. Studies in "transchromosomal" animal and non-human mammalian tissues suggest a high variability in the stability of engineered human chromosomes between tissue types and between genetic backgrounds. The meiotic transmission is clearly below that of endogenous chromo- somes (Irvine et al., 2005). Also in A. thaliana transgenerational inheritance of minichromosomes may vary between accessions (Murata et al., 2006). In maize, minichromosomes generated by transgene-mediated telomere seeding in A chromosomes were transmitted through meiosis to $33 \%$ of the progeny obtained by self-pollination or to $12 \%$ to $39 \%$ of progeny via male gametes (Yu et al., 2007), a rate similar to minichromosomes generated by breakage-fusion-bridge cycles (Kato et al., 2005). Transmission of truncated chromosomes was also below the rates expected from the Mendelian rules in progenies obtained by self-pollination in other plant species, accounting for $52 \%$ to $72 \%$ for tetraploid $A$. thaliana (Teo et al., 2011) and 54\% for tetraploid barley (Kapusi et al., 2012). Therefore, to ensure stable heritability, it seems important that genes are identified that code for genetic features linked with a high meiotic transmissibility of engineered chromosomes, such as by increased pairing and/or crossover frequency, and are included together with the genes for desired traits. It remains to be tested whether microinjection or microcell-mediated transfer will broaden the application of engineered chromosomes, in cases in which the transfer of plant minichromosomes via sexual crossing is not feasible.

\section{The next step: use of engineered plant minichromo- somes}

How can genes of interest be introduced into engineered minichromosomes? Targeted transgene integration into predetermined chromosomal loci might be achieved by using gene constructs in combination with a site-specific recombinase cassette as provided by the Cre/Lox system. As proof of principle (Yu et al., 2007), the engineered maize chromosome R2 provided a defined recipient locus for site-specific integration of transgenes, enabling genetic manipulation via site-specific recombination. After a plant carrying a Cre recombinase expression cassette and a Lox recombination site at the chromosome 3 terminus has been crossed with a plant carrying the defined recipient transgene at the de novo-formed telomere of the minichromosome R2, an active red fluorescent protein DsRed reporter gene was formed by reciprocal translocation of distal trangene ends via Cre/Lox recombination. Although the recombination efficiency was not as high as that observed in many non-plant organisms, this approach offers a possibility to add transgenes to a minichromosome. An engineered human chromosome had been used (Ayabe et al., 2005) to introduce the native human hypoxanthine phosphoribosyltransferase (HPRT)-encoding gene together with regions approximately $40 \mathrm{~kb}$ upstream and $10 \mathrm{~kb}$ downstream that included all regulatory elements needed for correct expression in Hprt -deficient cells, demonstrating a functional complementation. To establish targeted gene loading into the engineered chromosome, a transformation-associated recombination cloning of the gene-containing genomic fragment has been combined elegantly into a yeast artificial chromosome (YAC) vector (Kouprina et al., 1998) via Cre/Lox-based site-specific recombination of the circular YAC DNA into the recipient Lox site of the engineered human minichromosome (Ayabe et al., 2005). This method might be adaptable to plants as well.

In summary, the future is promising for engineered plant chromosomes as fascinating new tools for basic research on chromosomes, for biotechnology, and breeding purposes. The initial demonstration of the construction of plant chromosomes and their 
transmission behavior provides the foundation for this technology in plants, onto which further developments can be built. However, an increase in truncation efficiency, the introduction of multiple site-specific recombination systems, and the achievement of full meiotic transmissibility of site-specific recombination products are required before the commercial application of engineered plant chromosomes.

\section{Acknowledgements}

This publication was supported by the Leibniz Association (WGL) in the context of the "Pakt für Forschung und Innovation/WGL Wettbewerb 2009 - 2011 Leuchtturmprojekte".

\section{References}

AGUILERAA and GÓMEZ-GONZÁLEZ B (2008). Genome instability: a mechanistic view of its causes and consequences. Nat Rev Genet 9: 204-217.

ANANIEV E V, WU C, CHAMBERLIN MA, SVITASHEV S, SCHWARTZC, GORDONKAMM W and TINGEY S (2009). Artificial chromosome formation in maize (Zea mays L.). Chromosoma 118: 157-177.

AUFSATZ W, METTE M F, VAN DER WINDEN J, MATZKE A J M and MATZKE M (2002). RNA-directed DNA methylation in Arabidopsis. Proc Natl Acad Sci USA 99: 16499-16506.

AYABE F, KATOH M, INOUE T, KOUPRINA N, LARIONOV V and OSHIMURA M (2005). A novel expression system for genomic DNA loci using a human artificial chromosome vector with transformation-associated recombination cloning. $J$ Hum Genet 50: 592-599.

BARNHART M C, KUICH P H J L, STELLFOX M E, WARD J A, BASSETT E A, BLACK B E and FOLTZ D R (2011). HJURP is a CENP-A chromatin assembly factor sufficient to form a functional de novo kinetochore. J Cell Biol 194: 229-243.

BAUM M, SANYAL K, MISHRA P K, THALER N and CARBON J (2006). Formation of functional centromeric chromatin is specified epigenetically in Candida albicans. Proc Natl Acad Sci USA 103: 14877-14882.

BIRCHLER J A, KRISHNASWAMY L, GAETA R T, MASONBRINK R E and ZHAO C (2010). Engineered minichromosomes in plants. Crit Rev Plant Sci 29: 135-147.

BUERSTEDDE J-M and TAKEDA S (1991). Increased ratio of targeted to random integration after transfection of chicken B cell lines. Cell 67: 179-188.

BURT D W (2002). Origin and evolution of avian microchromosomes. Cytogenet Genome Res 96: 97-112.

CARCHILAN M, KUMKE K, MIKOLAJEWSKI S and HOUBEN A (2009). Rye B chromosomes are weakly transcribed and might alter the transcriptional activity of A chromosome sequences. Chromosoma 118: 607-616.

CARLSON S R, RUDGERS G W, ZIELER H, MACH J M, LUO S, GRUNDEN E, KROL C, COPENHAVER G P and PREUSS D (2007). Meiotic transmission of an in vitro-assembled autonomous maize minichromosome. PLoS Genet 3: e179.

CARLSON W R (1978). B-chromosome of corn. Annu Rev Genet 12: 5-23.

CLARKE $L$ and CARBON J (1985). The structure and function of yeast centromeres. Annu Rev Genet 19: 29-56.

CSONKAE, CSERPÁNI, FODORK, HOLLÓ G, KATONAR, KERESÖJ, PRAZNOVSZKY T, SZAKÁL B, TELENIUS A, DEJONG G, UDVARDY A and HADLACZKY G (2000). Novel generation of human satellite DNA-based artificial chromosomes in mammalian cells. J Cell Sci 113: 3207-3216.

DHAR M K, FRIEBE B, KOUL A K and GILL B S (2002). Origin of an apparent B chromosome by mutation, chromosome fragmentation and specific DNA sequence amplification. Chromosoma 111: 332-340.

FARRC, FANTESJ, GOODFELLOWP and COOKEH (1991). Functional reintroduction of human telomeres into mammalian cells. Proc NatIAcad SciUSA 88: 7006-7010.

GAETA R T, MASONBRINK R E, KRISHNASWAMY L, ZHAO C and BIRCHLER J A (2012). Synthetic chromosome platforms in plants. Annu Rev PlantBiol63:307-330.

GASCOIGNE K E, TAKEUCHI K, SUZUKI A, HORI T, FUKAGAWA T and CHEESEMAN I M (2011). Induced ectopic kinetochore assembly bypasses the requirement for CENP-A nucleosomes. Cell 145: 410-422.

GRIMES B R and MONACO Z L (2005). Artificial and engineered chromosomes: developments and prospects for gene therapy. Chromosoma 114: 230-241.
HAN F, LAMB J C and BIRCHLER J A (2006). High frequency of centromere inactivation resulting in stable dicentric chromosomes of maize. Proc Natl Acad Sci USA 103: 3238-3243.

HARRINGTON J J, VAN BOKKELEN G, MAYS R W, GUSTASHAW K and WILLARD HF (1997). Formation of de novo centromeres and construction of first-generation human artificial microchromosomes. Nat Genet 15: 345-355.

HOUBEN A and SCHUBERT I (2003). DNA and proteins of plant centromeres. Curr Opin Plant Biol 6: 554-560.

HOUBEN A, DAWE R K, JIANG J and SCHUBERT I (2008). Engineered plant minichromosomes: a bottom-up success? Plant Cell 20: 8-10.

IKENO M, GRIMES B, OKAZAKIT, NAKANO M, SAITOH K, HOSHINO H, MCGILL N I, COOKE H and MASUMOTO H (1998). Construction of YAC-based mammalian artificial chromosomes. Nat Biotechnol 16: 431-439.

IRVINE D V, SHAW M L, CHOO K H A and SAFFERY R (2005). Engineering chromosomes for delivery of therapeutic genes. Trends Biotechnol 23: 575-583.

JIN W, MELO J R, NAGAKI K, TALBERT P B, HENIKOFF S, DAWE R K and JIANG J (2004). Maize centromeres: Organization and functional adaptation in the genetic background of oat. Plant Cell 16: 571-581.

JONES N and HOUBEN A (2003). B chromosomes in plants: escapees from the A chromosome genome? Trends Plant Sci 8: 417-423.

JOVTCHEV G, WATANABE K, PECINKA A, ROSIN F M, METTE M F, LAM E and SCHUBERT I (2008). Size and number of tandem repeat arrays can determine somatic homologous pairing of transgene loci mediated by epigenetic modifications in Arabidopsis Thaliana nuclei. Chromosoma 117: 267-276.

JOVTCHEV G, BORISOVABE, KUHLMANN M, FUCHSJ, WATANABE K, SCHUBERT I and METTE M F (2011). Pairing of lacOtandem repeats in Arabidopsis Thaliana nuclei requires the presence of hypermethylated, large arrays at two chromosomal positions, but does not depend on H3-lysine-9-dimethylation. Chromosoma 120 : 609-619.

KABIR M A and RUSTCHENKO E (2005). Determination of gaps by contig alignment with telomere-mediated chromosomal fragmentation in Candida albicans. Gene 345: 279-287.

KAPUSI E, MA L, TEO C H, HENSEL G, HIMMELBACH A, SCHUBERT I, METTE M $F, K U M L E H N ~ J$ and HOUBEN A (2012). Telomere-mediated truncation of barley chromosomes. Chromosoma 121: 181-190.

KARPEN G H and ALLSHIRE R C (1997). The case for epigenetic effects on centromere identity and function. Trends Genet 13: 489-496.

KATO A, ZHENG Y Z, AUGER D L, PHELPS-DURR T, BAUER M J, LAMB J C and BIRCHLER J A (2005). Minichromosomes derived from the $B$ chromosome of maize. Cytogenet Genome Res 109: 156-165.

KATO N and LAM E (2001). Detection of chromosomes tagged with green fluorescent protein in live Arabidopsis Thaliana plants. Genome Biol 2: Research0045.1-0045.10.

KERESÖ J, PRAZNOVSZKY T, CSERPÁN I, FODOR K, KATONA R, CSONKA E, FÁTYOL K, HOLLÓ G, SZELES A, ROSS A R, SUMNER A T, SZALAY A A and HADLACZKY G (1996). De novo chromosome formations by large-scale amplification of the centromeric region of mouse chromosomes. Chromosome Res 4: 226-239.

KINOSHITA N, BERR A, BELIN C, CHAPPUIS R, NISHIZAWA N K and LOPEZMOLINA L (2010). Identification of growth insensitive to $A B A 3$ (gia3), a recessive mutation affecting ABA Signaling for the control of early post-germination growth in Arabidopsis Thaliana. Plant Cell Physiol 51: 239-251.

KOUPRINA N, ANNAB L, GRAVES J, AFSHARI C, BARRETT J C, RESNICK M A and LARIONOV V (1998). Functional copies of a human gene can be directly isolated by transformation-associated recombination cloning with a small 3 ' end target sequence. Proc Natl Acad Sci USA 95: 4469-4474.

LIM H N and FARR C J (2004). Chromosome-based vectors for mammalian cells: an overview. Methods Mol Biol 240: 167-186.

MARTIS M M, KLEMME S, BANAEI-MOGHADDAM AM, BLATTNER F R, MACAS J, SCHMUTZER T, SCHOLZ U, GUNDLACH H, WICKER T, ŠIMKOVÁ H, NOVÁK P, NEUMANN P, KUBALÁKOVÁ M, BAUER E, HASENEYER G, FUCHS J, DOLEŽEL J, STEIN N, MAYER K F X and HOUBEN A (2012). Selfish supernumerary chromosome reveals its origin as a mosaic of host genome and organellar sequences. Proc Natl Acad Sci USA 109: 13343-13346.

MENDIBURO M J, PADEKEN J, FÜLÖP S, SCHEPERS A and HEUN P (2011). Drosophila CENH3 is sufficient for centromere formation. Science 334: 686-690. 
MÜNTZINGA(1970). Chromosomal variation in the Lindström strain of wheat carrying accessory chromosomes in rye. Hereditas 66: 279-286.

MURATA M, SHIBATA F and YOKOTA E (2006). The origin, meiotic behavior, and transmission of a novel minichromosome in Arabidopsis Thaliana. Chromosoma 115: 311-319.

MURATA M, YOKOTA E, SHIBATA F and KASHIHARA K (2007). A ring minichromosome generated by T-DNA insertion in Arabidopsis Thaliana. Chromosome Res 15, Suppl 2: 71-72 (\#L.11.1).

MURATA M, YOKOTA E, SHIBATA F and KASHIHARAK (2008). Functional analysis of the Arabidopsis centromere by T-DNA insertion-induced centromere breakage. Proc Natl Acad Sci USA 105: 7511-7516.

MURATAM, SHIBATAF, HIRONAKAA, KASHIHARAK, FUJIMOTOS, YOKOTAE and NAGAKIK (2013). Generation of an artificial ring chromosome in Arabidopsis by the Cre/LoxP-mediated recombination. Plant J 74: 363-371 (doi: 10.1111/tpj.12128).

MURRAY A W and SZOSTAK J W (1983). Construction of artificial chromosomes in yeast. Nature 305: 189-193.

NAGAKI K, CHENG Z, OUYANG S, TALBERT P B, KIM M, JONES K M, HENIKOFF S, BUELL C R and JIANG J (2004). Sequencing of a rice centromere uncovers active genes. Nat Genet 36: 138-145.

NAKANO M, CARDINALE S, NOSKOV V N, GASSMANN R, VAGNARELLI P, KANDELS-LEWIS S, LARIONOV V, EARNSHAW W C and MASUMOTO H (2008). Inactivation of a human kinetochore by specific targeting of chromatin modifiers. Dev Cell 14: 507-522.

NASUDA S, HUDAKOVA S, SCHUBERT I, HOUBEN A and ENDO T R (2005). Stable barley chromosomes without centromeric repeats. Proc Natl Acad Sci USA 102: 9842-9847.

NELSON A D, LAMB J C, KOBROSSLY P S and SHIPPEN D E (2011). Parameters affecting telomere-mediated chromosomal truncation in Arabidopsis. Plant Cell 23: 2263-2272

PECINKA A, KATO N, MEISTER A, PROBST A V, SCHUBERT I and LAM E (2005). Tandem repetitive transgenes and fluorescent chromatin tags alter local interphase chromosome arrangement in Arabidopsis Thaliana. J Cell Sci 118: 3751-3758.

PHAN B H, JIN W, TOPP C N, ZHONG C X, JIANG J, DAWE R K and PARROTT W A (2007). Transformation of rice with long DNA-segments consisting of random genomic DNA or centromere-specific DNA. Transgenic Res 16: 341-351.

PUERTAS M J (2002). Nature and evolution of B chromosomes in plants: Anon-coding but information-rich part of plant genomes. Cytogenet Genome Res 96: 198-205.

RAYCHAUDHURI N, DUBRUILLE R, ORSI G A, BAGHERI H C, LOPPIN B and LEHNER CF (2012). Transgenerational propagation and quantitative maintenance of paternal centromeres depends on Cid/Cenp-A presence in Drosophila sperm. PLoS Biol 10: e1001434.

REISS B (2003). Homologous recombination and gene targeting in plant cells. Int Rev Cytol 228: 85-139.

RICHARDS E J and AUSUBEL F M (1988). Isolation of a higher eukaryotic telomere from Arabidopsis Thaliana. Cell 53: 127-136.
SCHUBERT I (2001). Alteration of chromosome numbers by generation of minichromosomes - Is there a lower limit of chromosome size for stable segregation? Cytogenet Cell Genet 93: 175-181.

SCHUBERT I and OUD J L (1997). There is an upper limit of chromosome size for normal development of an organism. Cell 88: 515-520.

SPENCE J M, MILLS W, MANN K, HUXLEY C and FARR C J (2006). Increased missegregation and chromosome loss with decreasing chromosome size in vertebrate cells. Chromosoma 115: 60-74.

TAMAR S and PAPADOPOULOU B (2001). A telomere-mediated chromosome fragmentation approach to assess mitotic stability and ploidy alterations of Leishmania chromosomes. J Biol Chem 276: 11662-11673.

TEO C H, MAL, KAPUSI E, HENSEL G, KUMLEHN J, SCHUBERT I, HOUBEN A and METTE M F (2011). Induction of telomere-mediated chromosomal truncation and stability of truncated chromosomes in Arabidopsis Thaliana. Plant J 68: 28-39.

TEO CH, LERMONTOVAI., HOUBENA, METTE M F and SCHUBERTI (2013). De novo generation of plant centromeres at tandem repeats. Chromosoma 122: 233-241.

TINLAND B and HOHN B (1995). Recombination between prokaryotic and eukaryotic DNA: integration of Agrobacterium tumefaciens T-DNA into the plant genome. In Genetic Engineering, Vol. 17 (Ed. JK Setlow) Plenum Press, New York, pp. 209-229.

TZFIRA T, LI J, LACROIX B and CITOVSKY V (2004). Agrobacterium T-DNA integration: molecules and models. Trends Genet 20: 375-383.

VEGA J M, YU W, HAN F, KATO A, PETERS E M, ZHANG Z J and BIRCHLER J A (2008). Agrobacterium-mediated transformation of maize (Zea mays) with Cre-lox site specific recombination cassettes in BIBAC vectors. Plant Mol Biol66:587-598.

VIG B K (1994). Do specific nucleotide bases constitute the centromere? Mutat Res 309: 1-10.

WATANABE K, PECINKA A, MEISTER A, SCHUBERT I and LAM E (2005). DNA hypomethylation reduces homologous pairing of inserted tandem repeat arrays in somatic nuclei of Arabidopsis Thaliana. Plant J 44: 531-540.

WILSON III D M and THOMPSON L H (2007). Molecular mechanisms of sisterchromatid exchange. Mutat Res-Fundam Mol Mech Mutagen 616: 11-23.

WUEBBLES R and JONES P L (2007). Engineered telomeres in transgenic Xenopus laevis. Transgenic Res 16: 377-384.

XU C, CHENG Z and YU W (2012). Construction of rice mini-chromosomes by telomere-mediated chromosomal truncation. Plant J 70: 1070-1079.

YOKOTAE, NAGAKI K and MURATAM (2010). Minichromosome stability induced by partial genome duplication in Arabidopsis Thaliana. Chromosoma 119: 361-369.

YOKOTAE, SHIBATAF, NAGAKI Kand MURATAM (2011). Stability of monocentric and dicentric ring minichromosomes in Arabidopsis. Chromosome Res 19: 999-1012.

YUW, LAMB J C, HAN F and BIRCHLER JA(2006). Telomere-mediated chromosomal truncation in maize. Proc Natl Acad Sci USA 103: 17331-17336.

YU W C, HAN F, GAO Z, VEGA J M and BIRCHLER J A (2007). Construction and behavior of engineered minichromosomes in maize. Proc Natl Acad Sci USA 104: 8924-8929. 


\section{Further Related Reading, published previously in the Int. J. Dev. Biol.}

Comparative expression analysis of the H3K27 demethylases, JMJD3 and UTX, with the H3K27 methylase, EZH2, in Xenopus Akane Kawaguchi, Haruki Ochi, Norihiro Sudou and Hajime Ogino Int. J. Dev. Biol. (2012) 56: 295-300

Female gametophytic mutants of Arabidopsis Thaliana identified in a gene trap insertional mutagenesis screen Vladimir B. Brukhin, Miloslawa Jaciubek, Arturo Bolaños Carpio, Vera Kuzmina and Ueli Grossniklaus Int. J. Dev. Biol. (2011) 55: 73-84

Comparison of reprogramming ability of mouse ES and iPS cells measured by somatic cell fusion Huseyin Sumer, Craig Nicholls, Jun Liu, Pollyanna A. Tat, Jun-Ping Liu and Paul J. Verma Int. J. Dev. Biol. (2010) 54: 1723-1728

Natural and artificial routes to pluripotency

Winfried H. Krueger, Lindsey C. Swanson, Borko Tanasijevic and Theodore P. Rasmussen Int. J. Dev. Biol. (2010) 54: 1545-1564

Essential validation of gene trap mouse ES cell lines: a test case with the gene Ttrap Liesbeth Vermeire, Abdelilah Ibrahimi, Thierry Voet, Lieve Umans, Kathleen Coddens, Annick Francis, Tom Van de Putte, Leo A. van Grunsven, An Zwijsen, Danny Huylebroeck and Luc Nelles

Int. J. Dev. Biol. (2009) 53: 1045-1051

Distribution of p53 binding protein 1 (53BP1) and phosphorylated H2A.X during mouse preimplantation development in the absence of DNA damage Céline Ziegler-Birling, Anne Helmrich, Làszlò Tora and Maria-Elena Torres-Padilla Int. J. Dev. Biol. (2009) 53: 1003-1011

Common themes in siRNA-mediated epigenetic silencing pathways André Verdel, Aurélia Vavasseur, Madalen Le Gorrec and Leila Touat-Todeschini Int. J. Dev. Biol. (2009) 53: 245-257

Inadvertent presence of pluripotent cells in monolayers derived from differentiated embryoid bodies

Miguel A. Ramírez, Eva Pericuesta, Raúl Fernández-González, Belén Pintado and Alfonso Gutiérrez-Adán

Int. J. Dev. Biol. (2007) 51: 397-408

Historical perspectives on plant developmental biology Mieke Van Lijsebettens and Marc Van Montagu Int. J. Dev. Biol. (2005) 49: 453-465

5 yr ISI Impact Factor $(2011)=2.959$
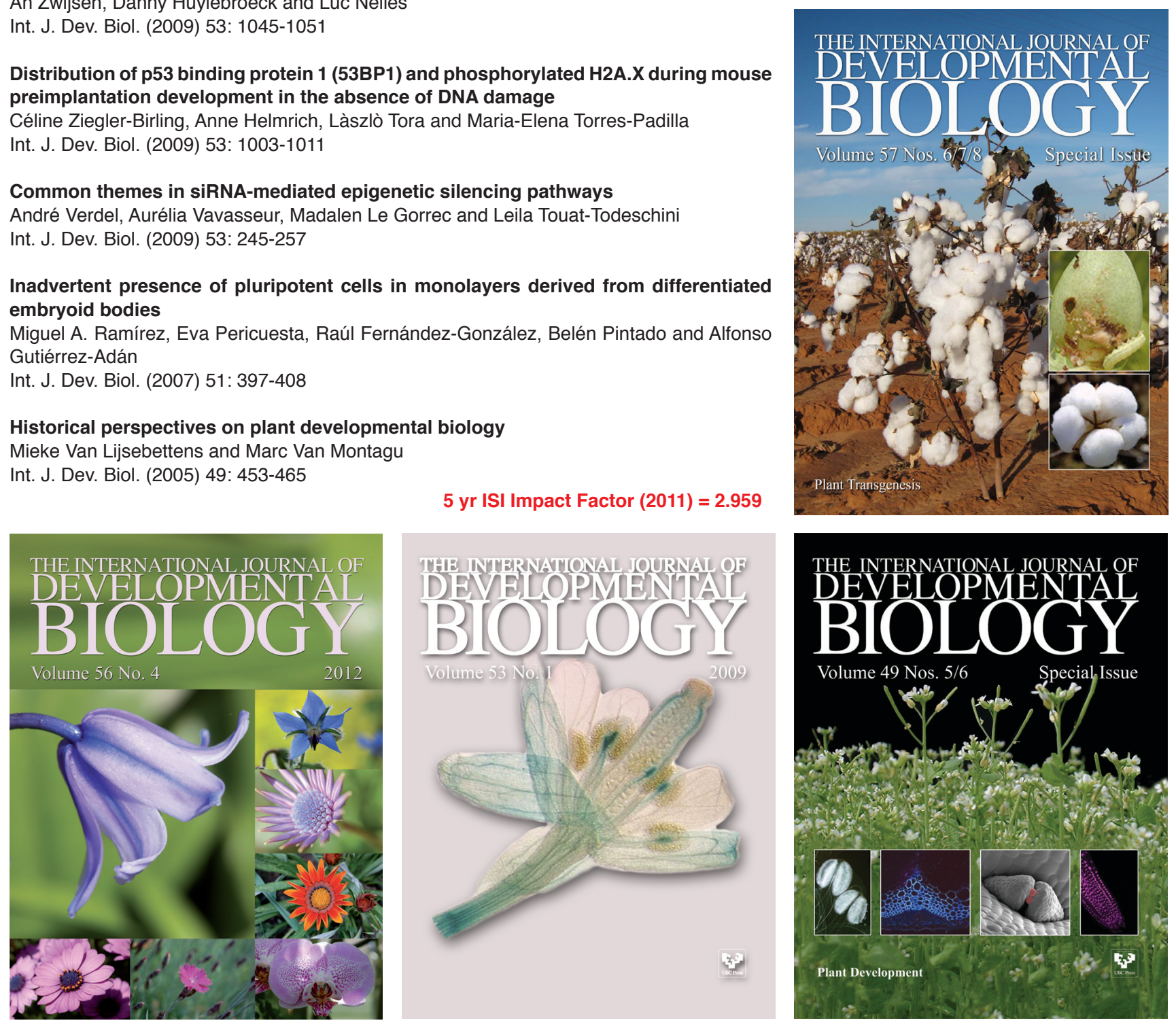